Copyright (C) 2015 by Academic Publishing House Researcher

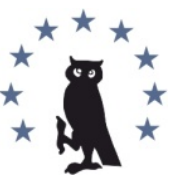

Published in the Russian Federation

European Researcher

Has been issued since 2010 .

ISSN 2219-8229

E-ISSN 2224-0136

Vol. 93, Is. 4, pp. 298-306, 2015

DOI: $10.13187 /$ er.2015.93.298

www.erjournal.ru

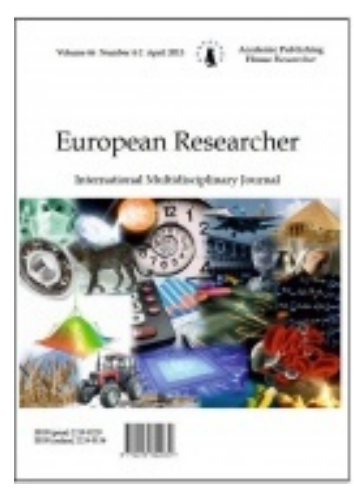

Philological sciences

Филологические науки

UDC 82.00

\title{
Modern Sound of Themes "War" and "Peace" in the Poem "Two Hundred Ten Steps" By R. I. Rozhdestvenskiy
}

Nina Ya. Sipkina

Khakassia State University named by N.F. Katanov, Russian Federation

655000, Republic of Khakassia, Abakan, Lenin Ave., 90

The Candidate of Philology, Associate.

Email: sipkina.nina@yandex.ru

\section{Abstract}

This article focuses on the thematic content of the poem "Two hundred and ten steps" by R.I. Rozhdestvenskiy in the context of the literary process of the 1970s. The scientific novelty of the test material is the first time in the domestic literary study one of the most important poems in the work of R.I.Rozhdestvenskiy. Chapter explores the poem on the themes of war and peace. The article reveals the moral and aesthetic principles of the poet, his attitude to topical issues of global importance.

Keywords: R.I.ROZHDESTVENSKIY; poem; "Two hundred and ten steps"; theme; war; peace; moral and aesthetic principles; structure; style; images; trails; lyricism; journalistic.

\section{Введение}

Актуальной проблемой современного отечественного литературоведения становится изучение поэтического наследия Р.И. Рождественского. Творчество поэта, также как и творчество фактически всех его соратников (Е.А. Евтушенко, А.А. Вознесенского, Б.А. Ахмадулиной и др.) - недостаточно изученная страница истории русской литературы второй половины XX века, вобравшая в себя сорокалетний опыт развития художественного и общественного сознания страны. Произведения Р.И. Рождественского - важная часть историко-литературного развития, совпадающая и, в какой-то мере, определяющая общий ход развития русской поэзии второй половины XX века.

Материалы и методы. Основным источником для написания данной статьи стала поэма «Двести десять шагов» Р.И. Рождественского, литературоведческие исследования по истории развития русской литературы вт. пол. ХХ в., в том числе поэзии «шестидесятников», которая является неотъемлемой частью литературного процесса 2 пол. XX века. Методологическую основу исследования составили труды известных российских литературоведов, теоретиков литературы, философов (А.Ф. Лосева, Ю.И. Минералова, 
А.А. Потебни, В.П. Прищепы, Л.И. Тимофеева, Ю.Н. Тынянова, Б.В. Томашевского, В.Е. Холшевникова, Б.М. Эйхенбаума и др.). Данная работа построена на дедуктивном методе: поэма «Двести десять шагов» Р.И. Рождественского рассматривается не как совокупность отдельных признаков, но как целостная структура, имеющая ряд взаимообусловленных функций. В работе использованы методы, предполагающие изучение поэмного жанра вт. пол. $\mathrm{XX}$ в. в его социально-историческом развитии: аналитический, культурно-исторический, контекстологический, сравнительно-сопоставительный. Ракурс избранных методов продиктован общей исследовательской задачей и, на наш взгляд, позволит выявить современное звучание темы «войны и «мира» в поэме «Двести десять шагов», определить роль анализируемой поэмы в поэмном творчества Р.И. Рождественского.

\section{Обсуждение}

В ряду поэтических произведений Р. И. Рождественского поэма «Двести десять шагов» (1978) носит значимый характер. Тема «войны» и «мира», отображённая в поэме, как никогда актуальна и современна. В 1970-е гг. (времени написания поэмы) существовал политический барьер между странами мира, который и сейчас (в начале XXI века) не исчез, а обострился с новой силой. Людей мирового сообщества беспокоит расползающаяся по всему миру агрессия. Нашему земному дому грозит беда: суперсовременные ядерные и водородные бомбы в течение нескольких минут могут уничтожить человеческую цивилизацию и всё живое на земле. Роль писателей в защите мира огромна. Эта волнующая тема постоянно звучит в стихах и прозе современных писателей (Е. Евтушенко, А. Архангельский, В. Распутин, Б. Гребенщиков, Т. Кибиров и др.). Читателям объясняется, что в третьей мировой войне победителей не будет - всё живое погибнет.

В статье «Шаги истории: за строкой поэмы» («Литературная газета» 20 декабря 1978 г.) Р.И. Рождественский раскрывает причину постоянного возвращения к военной тематике, памяти о ней в своих стихах и поэмах: «Хотя сам я не воевал, но о войне писал довольно много. В «Реквиеме», созданном полтора десятилетия назад, я пытался выразить тогдашнее свое понимание этой высокой темы. Но память - не нечто застывшее, она взрослеет вместе с человеком. Приходит, может быть, не другое, но несколько иное понимание событий, связи их с сегодняшним днем. Можно сказать, что память с годами углубляется...» $[1$, с. 3$]$.

А в беседе с В. Жегисом («Литературная газета», 2 мая 1980 г.), на вопрос, какая тема главная для поэта, Р.И. Рождественский ответил: «Говорят, что самые сильные воспоминания - это воспоминания детства. Для меня оно совпало с войной. И хотя я не слышал свиста пуль и разрыва бомб, все равно дыхание войны опалило мою душу. Память возвращает меня в далекие годы. Вот я стою на затемненном вокзале, провожая на фронт отца. И не нахожу нужных слов на прощание. Вот вместе с матерью, военным врачом, я, «сын полка» и страшно гордый своим необычным званием, еду из Омска, где перед войной жила наша семья, в Москву. Вот я курсант военно-музыкального училища, шагаю в шеренге то по улицам столицы. И далеко разносятся наши голоса под звуки воинского марша. Помню молчаливые очереди у хлебных магазинов. Шаркающие по лестнице шаги старенького почтальона (что у него в сумке - радость или беда?). И постоянное ожидание Победы» [2, с. 3].

Теме войны посвящена одноимённая глава в поэме «Двести десять шагов». Глава написана в жанре баллады. Перед читателем разворачивается история краткой жизни и бессмертного подвига, первый и последний бой «новоиспечённого» лейтенанта: «Было училище. / Форма - на вырост. / Стрельбы с утра. / Строевая - зазря... / Полугодичный ускоренный выпуск. / И на петлице - два кубаря...» [3, с. 169] .

В содержании главы «Война» можно различить автобиографические штрихи - автор поэтизирует детские воспоминания о «путешествии» из Омска в Москву с мамой, военврачом, Верой Павловной в военном эшелоне. Они едут очень медленно, подолгу останавливаясь на каждой станции (стихотворение «В сорок третьем»). В поэме мы читаем: «Шёл эшелон / по протяжной / России, / шёл на войну, / сквозь мельканъе / берёз» [3, с. 17о].

В образе молодого лейтенанта-мальчишки можно узнать черты и самого поэтаподростка: «..он по дороге взрослел - / этот мальчик - / тонкая шея, / уши торчком.../ Только во сне, оккупировав полку / в осатанелом / табачном дъму...» [3, с. 170]. 
В поэме война - это катастрофа. На протяжении всей главы перед читателями разворачивается картина трагедии. «Шёл эшелон. / А навстречу, навстречу - / лишь санитарные поезда..», «..Воздух наполнился громом, / әуденъем. / Мир был изломан, / бъл искажён...») [3, с. 170] .

Строки «Станции / как новгородское вече», «Полночь / была, как курок / взведена...», «Будто бы эта планета / кончалась / там, / где сейчас наступали / враги! / Будто её становилось всё менъше!..» помогают представить нам драматическую, напряженную обстановку «глобального передвижения людского потока», в котором можно легко затеряться, погибнуть. В содержании главы умозрительно представляется сужение пространственных и временных образов-картин.

Ужасы и кошмары войны передаются с помощью образов-тропов - метафор: «Mup, / где клокочет людская беда», «Мир был изломан, / был искажён... / Это / казалось ошибкой, / виденъем, / странным, / чудовищным миражом..», «Дыбились шпаль! / насыпь качалась! / Кроме пожара, / невидно ни зги» [3, с. 171].

Рефреном-клятвой звучат слова под стук колёс вагона в голове лейтенанта: «Мъ разобъём их!..» / Мы их осилим!..» / «Мы им докажем!...» [3, с. 17о].

Интонационное напряжение достигает своего апогея в описании первого и последнего боя «новобранца». Трагична встреча лейтенанта со своей «судъбой-войной», как с «бедойсуженной»: «Танки!!.» / И сразу истошное: / «К бою!....» / Так они встретилисъ: / Он / и Война...» [3, с. 171]. Страх вызвала эта встреча, «судъбой предназначенная»: «...чёрный, / растерянный, / онемевший, - / в жёстком кювете / лежал лейтенант» [3, с. 172].

Риторические обращения лирических героев поэмы к молодому командиру звучат, как «Слово» перед боем к воинам, взывающее их к храбрости в защите самого святого на земле - Родины, а для этого не страшно отдать и свою собственную жизнь - ради существования будущего. Так жертвовали божественным бесценным даром наши далёкие и близкие предки-воины, защищая русскую землю от захватчиков. Преодолеть страх перед смертью «просят» лейтенанта (используется художественный приём - градация, образы-символы) «дом», «город», «Отечество», «мама», «природа», «незнакомая девчонка», «Чемпионы двора по футболу», «Маршал», «крейсер Аврора», «Тельман», «Солнце», «Гагарин», «не рождённые дети»: «Встань, / лейтенант!..»

Мальчишка-лейтенант «услышал» страстные призывы: «И тогда / встал / лейтенант. / И, шагнув по планете, выкрикнул не по уставу: / «Айда!!» [3, с. 17о]. Командой-просторечьем «Айда!» поэтом показано, что русским воином была преодолена грань страха, отделявшая смерть и жизнь. Он предложил своим бойцам, как будто прогуляться в парке отдыха под музыку свиста пуль и взрывов гранат и бомб.

Гибель лейтенанта - это гибель его внутреннего мира. Смерть - «бесконечная тишина» - совмещение временного пространства: «Встал лейтенант!.. / И наткнулся / на пулю. / Большую и твёрдую, / как стена.../ Вздрогнул он, / будто от зимнего ветра. / Падал он медленно, / как на распев. / Падал он долго... / Упал он / мгновенно. / Он даже выстрелить / не успел!» [3, с. 174]. Символичен образ «смерти-подвига»: «Чем этот бой завершился - / не знаю. / Знаю, / что кончилась / эта война!..» - в этом авторском умозаключении звучит бессмертие подвига молодого лейтенанта, который пал, не успевший даже выстрелить. Заклинанием звучат слова поэта о вечной памяти погибшим солдатам: «Мы про них / не вспомним, - / и про нас не вспомнят!»

В главе явно различима перекличка с поэмой «Реквием» (1960) Р. Рождественского. В «Реквиеме» (8 глава) есть строчки: «...И летят облака / над нами... / Приближается время дождей / Нарастающий ветер / колышет / большие хлеба...» [3, с. 38], в поэме «210 шагов» продолжается тема «Реквиема»: «... А над домом тучи / кружат-ворожат. / Под землёй цветущей / павшие / лежат. / Дождь / идёт над полем...» [3, с. 175].

С точки зрения интонационного рисунка для данной главы характерно сопряжение патетики и лиризма: «Не вспомнят / ни разу. / Никто / и никогда. / Бежит / по оврагу / мутная вода... / Вот и дождь / кончился. / Радуга / как польмя... / А ведь очень / хочется, чтоб и про нас / помнили!» [3, с. 175].

В беседе с В. Жегисом («Литературная газета», 2 мая 1980), на вопрос, какие современные проблемы волнует творческое воображение, Р.И.Рождественский ответил: 
«Это тема Памяти. Она относится, несомненно, к разряду вечных тем и в искусстве, и в жизни» [2, с. 3].

А. А. Потебня утверждал: «...поэзия есть преобразование мысли посредством конкретного образа, выраженного в слове, она есть создание сравнительно обширного значения при помощи единичного словесного образа» [9, с. 18-19].

Афоризм: «Память / за прошлое держится цепко» [3, с. 144], открывает жизненно важную для поэта тематику его творчества - памяти - в монологе «Лирическое отступление о школьных оценках».

Отталкиваясь от старинных школьных оценок «успевает» и «не успевает», и, используя многозначность этих слов, Р. Рождественский, оценивая свою жизнь, выставляет себе оценку - «не успевает» (11 раз).

Вслед за М.Н. Эпштейном [5, с. 252-256], мы определили, что художественные образы в поэтическом творчестве Р.И. Рождественского обладают «двучленностью». Это пересечение предметного и смыслового рядов словесно-обозначенного и подразумеваемого, где в образе один предмет является через другой, происходит их взаимопревращение (многочисленные тропы в стихах), что и позволяет стягивать разнородные явления в одно целое.

Оценка «не успевает» принимает на себя функцию основного образа, и уже от него разворачивается картина, по каким «пунктам», «предметам» жизни «не аттестован», отстал лирический герой поэмы. Оценка-рефрен - «не успеваю» помогает определить нам драматическое состояние души поэта. Он «не успевает» пообщаться с природой («довериться лесу», «Птицу послушать», «Ветку потрогать»), прочитать книги («Книги / квартиру / заполнили. / Я прочитать их / не успеваю!..»), выслушать школьного друга («Школьного друга / нежданно встречаю. / «Здравствуй! / Ну как ты?..» / И - / не успеваю / вслушаться / в то, что он мне / отвечает...»), подумать («Надо бы / попросту сесть и подумать!... / Не успеваю!»), сделать счастливой любимую женщину («Женщину, / самую лучшую / в мире, сделать счастливой / не успеваю!»), написать главное («А написать / свои главные строки / не успеваю!» [3, с. 144-146].

В главе звучит субъективная оценка собственной жизни лирического героя неудовлетворительная. Эта одна из немногих глав поэмы, в которой нам раскрывается «истинное лицо» лирического героя-поэта, задыхавшегося от невозможности что-то изменить и в своей, и в окружающей жизни. У него исчезают иллюзии в веру победы в нашей стране «социализма с человеческим лицом». В исследуемой главе мы не найдём риторики и деклараций. Трагизм ощущается в каждой стихотворной строчке. «Мрачные» метафоры подтверждают безнадёжность жизненной ситуации: «Время жалею. / Недели мусолю»; «Вижу / всё больше вечерние / зори. / Утренних зорь / я почти что не помню», «Книги / квартиру / заполнили», «Снова ползу / в бесконечную гору, / и от встречного ветра / немею».

Голоса лирического героя-поэта никто не слышит, а собственная жизнь представляется ему чем-то ужасным (сравнения: «В душном вагоне - / будто в горниле», «Как протодьякон / в праздничной церкви, / голос / единственный / надрываю..»).

Героя-поэта окружает: «Аэродромный разбойничий рокот»; «Липкий мотив»; «бессмысленно спорю», «нежданно встречаю»), отсюда и соответствующее настроение лирического героя («непонятной хандры», «Отодвигаю / и планы и сроки») и действия (нагнетание глаголов: «довериться», «послушать», «потрогать», «бегу», «подуют», «изнываю»).

Но, всё-таки, Роберт Рождественский - поэт «оттепели» - в его творчестве остаётся способность говорить намёками, которые ясны читателю-современнику (эвфемизмы: «Знаю, / что скоро метели / подуют», «Слушаю притчи / о долготерпенъе»).

Контрастно по содержанию «Лирическим отступлениям о школьных оценка» звучит глава «Нелирическое отступление о дорогах» Жанровая разновидность главы публицистический монолог, в котором звучит актуальная тема - состояние дорог в нашей стране. Даже сам автор утверждает: «Не ищите поэзии / в данной главе! / Не считайте ее / стихами!.. / Не стихи пишу / хрипльм криком / кричу. / Не себе / прошу - / для Отчизны / хочу» [3, с. 166].

Из беседы критика А. Мальгина с Р. Рождественским нам открывается ещё одна отличительная черта в творчестве поэта - публицистичность: 
«- Роберт Иванович, в вашем творчестве очень сильна публицистическая струя. Не исключение и ваши поэмы. Даже в такой пафосной вещи, как «Двести десять шагов», немало открыто публицистических, «газетных» фрагментов. Например, «Нелирическое отступление о дорогах», в котором вы с болью пишете о состоянии дорог в нашей стране...

- Да, вы знаете, после опубликования вещи мне пришло письмо из Министерства автомобильных дорог РСФСР, в котором сообщалось, что министр включил эту главку в свой приказ по министерству...» [6, с. 19-23].

Из воспоминаний поэта А. Дементьева мы узнаём историю «хождения в народе» фразы-афоризма из данной главы: «В общем, он (Роберт Рождественский) никогда не терялся, остроумие помогало ему выходить из любых ситуаций. Я помню, он придумал фразу: «Коммунизм есть Советская власть плюс дороги». В то время такие фразы не были в почете. Нельзя было что-то неожиданное заявлять, что накладывалось на какую-то доктрину, которая была спущена нам Лениным, Сталиным, временем, Политбюро. А Роберт всё это делал, он мог. И фраза стала расхожей» [7, с. 355-358].

В главе можно прочесть несколько афористических высказываний о значении дорог в жизни людей нашей страны. В одном из них «дорога» приобретает символический образ человеческой жизни: «Все когда-нибудь / делают шаг / за порог. / Жизнь у всех - / на дорогах бренных...» [3, с. 164]. Выражение «дорогах бренных» говорит нам о кратковременности людской физической жизни. Умозаключениями: «A мечтаю $я$ / $o$ пятилетке дорог» [3, с. 164]. «Но в Державе такой, / в Государстве таком / бездорожье / уже безнравственно!» [3, с. 166]. Р. Рождественским поднимается идейно-этическая подоплёка значения системы дорог в российском отечестве. А заключительный афоризм «..коммунизм / есть / Советская власть / плюс дороги!» [3, с. 167] претендует уже на роль «новой доктрины» в советской идеологии.

Поэтический стиль главы ироничен по своему характеру. Например, иронично звучит метафорическое описание состояния российских дорог: «...в чернозёмах / и в глинистой жиже / стонут в голос, / воюют, / ревут ревмя / на конкретнъх дорогах / машины!» [3, с.164]. Драматизм ситуации, выраженный с помощью гиперболы: «Даже если какая беда пришла, то доехать / в средине марта / от села одного / до другого села - / Ни рессор не хватит, / ни мата!..» [3, с. 165] звучит «смехом сквозь слёзы».

В рассуждении о цене, которую платят россияне за неудовлетворительное состояние дорог, критикуется российское «головотяпство», как «менталитет» русского правления, начиная со времён «царя-гороха». Данной цели поэт достигает с помощью остроумия игрой слов-омонимов: «Знаю в слове «до-ро-га» / звенит цена, - / Дорогше нынче / дороги!.. / Ладно, дорого...» [3, с.165].

В одной из бесед Р. Рождественский признался «Я очень люблю Москву, с которой у меня с детства много связано» [6, с. 19-23]. Глава «Утреннее отступление о Москве» звучит как признание в любви городу-столице. Это пейзажная зарисовка, лёгкий набросок из жизни утренней Москвы.

Как сердцебиение, с волнением звучит рефрен, соединяющий потоки авторской мысли о любимом городе: «Нас у Москвы - очень много...» [3, с. 175], «Нас у Москвы очень много, / много нас / у Москвы!» [3, с. 178], а заключительный повтор уже носит афористический характер, раскрывающий значение Москвы для москвичей: «Нас у Москвы / оченъ много. / А Москва у нас - / одна» [3, с. 179].

Ещё одним афоризмом: «Город - / всегда диалог / прошлого / с настоящим» [3, с. 175] автор доказывает взаимосвязь времени с историей города, с её путём. Образ дороги приобретает здесь символический характер: «В городе - / сотни дорог, / вечность / в себе / таящих» [3, с. 176].

Данная глава отличается лиризмом. Перед читателями раскрывается образ города как живого существа. Мы наблюдаем счастливую картину просыпающегося мирного утреннего города: «и задышало метро», «Вот / добежав, / дотикая, / пробуя голос свой, / полмиллиона будильников / грянули / над Москвой! / Благовест наш / небогатый, / утренний наш набат...», «.. плюхаются / на сковородку / солнечные / желтки!..», «Будто гигантский / поршень, / в доме / работает лифт!..» [3, с. 175-179];

Экспрессивное выражение: «И снова, идя на рожсон, мужъя / забором газетным / отгородились / от жён» [3, с. 177], вносит нотку юмора в содержание главы. 
Следующая глава «Мир», как и глава «Нелирическое отступление о дорогах», носит публицистический характер. В ней раскрывается актуальная проблема земного человеческого сообщества - гонка вооружения и сохранение мира на нашей планете.

В интервью («Литературная газета», 5 ноября 1980 г.) Р. Рождественский говорил: «..речь действительно идёт о нашей общей судьбе, о судьбе всего земного шара... Остановить гонку вооружений стало не только делом чести, но и делом жизни Человечества... Ещё несколько лет назад я читал в американском журнале статью какого-то отставного военного. И он, хвастаясь американской мощью, заявлял, что количество ядерных боеголовок, накопленных США, достаточно для того, чтобы уничтожить Советский Союз и весь социалистический лагерь 17 раз! И что, дескать, СССР способен сделать то же самое с Америкой только 12 раз. Вывод, который сделал отставной генерал безумен, как и все его рассуждения, американцы сильнее русских... Но разве для того, чтобы уничтожить человека, не хватит одного единственного раза? И разве можно относиться к этому равнодушно? Защита мира - наш долг, главное дело нашей жизни, наш нынешний Мамаев курган...» [8, с. 3].

А в беседе с корреспондентом Литературной газеты (1980, 2 мая) на вопрос о цифре пятнадцать тони взрывчатки на каждого земного человека - упомянутой в поэме «210 шагов», Р. Рождественский ответил: «Я обнаружил её в данных ЮНЕСКО, Наверное, сейчас, по прошествии времени, эта цифра выросла. И она, я убежден, будет иметь тенденцию к увеличению до тех пор, пока во всем мире не восторжествует, наконец, разрядка, за которую так последовательно выступает наш народ, наше правительство» [2, с. 3].

Начинается глава парадоксальным умозаключением: «Мы - / жители Земли - / богатыри», которое звучит как «теорема».

Глава разъясняет высказанную мысль: образно подтверждается «богатырство» земных жителей. На протяжении всей главы доказывается несостоятельность непосильной тяжести, взвалившейся на плечи землян.

C точки зрения художественного оформления для главы характерны сатирические приёмы, которые предают главе черты памфлетности и самоирония: явно звучит перекличка с поэмой «До твоего прихода» (1965) Р. Рождественского: «Несу на горбу, / ...чужую судъбу. - /слепые/ слова... » [3, с. 109] - в «210 шагах» поэт продолжает: «... мы тащим тяжесть / на своих плечах... / промчавшихся годов...». Значение слова «тяжести» конкретизируется - ежедневная суетность, бесцельность существования: «пустьх надежд / и долгих холодов, / отметины от чьих-то губ / и рук, / нелепых ссор / бессмысленных разлук, / случайных дружб/ и не случайных встреч» [3, с. 179].

Иронично звучит афоризм: «Привъцнъй груз / не весит ничего...» [3, с. 179].

Р.И. Рождественский использует и сарказм: в парадоксальных выражениях: «...любой из нас / несёт пятнадцать тонн (взрывчатки)!..» [3, с. 180], «Пятнадцать тонн / на слабенъких плечах (новорождённого)! / Вот почему / все дети / так кричат...», « А ноша эта - ... / придумана и создана / людъми! / Людъми самими / произведена. / В секретные бумаги / внесена. / Нацелена / и взвешена уже..», «Взрывчатки - вдоволь. / Хлеба - / ни куска» [3, с. 180-183] звучит резкая, язвительная насмешка над стремлением правителей государств нашей планеты забавляться в «игру»: «Кто больше сделает бомб-убийц».

Саркастичны по характеру также и экспрессивные выражения: «...что, сколько их (бомб), / не знает даже бог!..», «...чёрт её (ношу) возъми!» [3, с. 180-183].

Иронично звучит рассуждение-умозаключение: «Но... если / разделить/ взрывчатку ... / на всех людей.../... И несёт любой из нас / пятнадцать тонн взрьвчатки»; «Богатъфри! / Я уважаю / вас...», «Пока - пятнадцать тонн» [3, с. 180-183].

В концепции А.А. Потебни «в образах-тропах реализуется процесс поэтического мышления художника. Образность отдельных слов и постоянных сочетаний, как бы ни была она заметна, ничтожна сравнительно со способностью языков создавать образы из сочетания слов, всё равно, образных или безобразны...» [4, с. 17].

Чувство бесконечной тревоги за судьбу нашей планеты, взвалившей непосильную «ношу», звучит в словах поэта. Так, в поэме перефразируется образ из известной поговорки «Сидеть на пороховой бочке» (в значении «находиться в крайне рискованном положении») во много раз увеличивая «крайне рискованное положение»: «...И снова ночь / висит над головой. / Бездонная, / как склад пороховой» [3, с. 183]. 
А. Мальгин в своём очерке «Р. Рождественский» утверждал: «Принципиальная удача поэта - глава «Пуля», которой завершается поэма «Двести десять шагов...» [9, с. 157 - 161].

Глава «Пуля» написана в форме диалога-спора. Завязка главы носит биографические черты. Можно утверждать, что она посвящена памяти рано ушедшего из жизни друга поэта - Юстаса Красаускаса - литовского художника-графика, актёра и спортсмена. Медицина оказалась беспомощной: «Поэт хирургии / полсуток стоял у стола. / Хотел опровергнуть прогнозы. / И - не опроверг. / Там не было / пули...» [3, с. 186]. Безнадёжность ситуации достигается с помощью использования ассоциативной рифмы практически каждое слово имеет внутреннюю рифму: «Поэт хирургии / полсуток стоял у стола. / Хотел опровергнуть прогнозы. / И - не опроверг. / Там не бъло / nyлu.... Друг умер от рака. Но вопреки утверждениям, поэт решает - от пули. Образ пули приобретает символический характер. Пуля, как смерть, судьба, стоящая перед каждым человеком. От этого образа-символа разворачивается содержание главы.

Афоризм: «На любом надгробъе - / два / главньх года: / год прихода в этот мир. / И год ухода» [3, с. 186] подтверждает мысль поэта, полную пессимизма, о «бренности» человеческого существования. Данное высказывание подтверждается сравнением: «между датами - черта, / как след от пули!» [3, с. 186-189] и расширенным сравнительным оборотом: «Значит, все-таки / была / пуля эта! / Значит, всё-таки / смогла / долго мчаться! / Значит, всё-таки / ждала / дня и часа! / Всё ждала она / ждала, / Всё летала! / И - / домчалась. / Дождаласъ. / Досвистела...»[3, с. 187]. Последнюю строфу отличает стиль былинного сказа: повторы - тавтологические рифмы («Значит, всё-таки», «Всё», «ждала»), глаголы-рифмы («была», «смогла», «ждала», «летала»), начальные рифмы («домчаласъ», «дождалась», «досвистела»), кольцевая рифмовка: («пуля эта», «долго миатся», «дня и часа»).

Символичен и образ дороги, обозначает земные, прожитые годы человека. Образ «дороги-жизни» и «пули-смерти» «сплетается в клубок» и становится двуединым, и уже нельзя одну отделить от другой: «От порога / до другого порога / въётся-кружит по земле / твоя дорога. / Въётся-кружит по земле / твоя усталость», «..обрываются / надежды и хвори! / Обрываются / мечты и печали!», «Два числа на камне / время стирает. / След от пули / между ними / пылает!..» (метафоричные высказывания)[3, с. 186-189].

Философское рассуждение о жизни и смерти выражается с помощью рефрена («эти пули летят», «а они летят», «а пули летят», «а пуля летит!», «А пуля смеётся, летя»), обрамляющего рассуждения лирического героя о суетно-бесцельной жизни.

В данной главе образ пули сравнивает с «суженной», встреча с которой обязательно состоится, несмотря ни на что: «И нельзя отсидеться в броне, / уехать, забраться..». Нельзя предугадать движение пули- «судьбы»: «Ударит (пуля) / в какой стороне / и с какой стороны?..», «И вновь / суматошные дни / суетою полны», «Вот что-то не сделал: «Успею...» / «Доделаю после..» «..весёлая пуля, / проклятая пуля..», «забытые богом края...», «Постой! / Да неужто / не может промазать она?!»

Символичен и образ Времени, который «судит» поступки лирического героя: «..наполнившись ветром, / осенние сосны гудят / желтеют в витринах / газеты / вчерашнего дня...», «В сырое окно / неподкупное время / глядит. / И небо / в потерянных звёздах, / как в каплях / дождя...» [3, с. 187-188].

Заключительная часть главы «Пуля» контрастна по-своему содержанию, в которой сочетается патетика и лиризм: «Да будет памятным / каждый / прошедший денъ! / А каждый грядущий день / да будет воспет!..» и «Над детским дъхханъем / склонилась / усталая мать», «В оттаявшем небе - / рассветная полоса...»[3, с. 188].

Высказывания-рефрены «пронзают» содержание заключительной главы подобно «пулям»: «На то мы и люди» (строчка повторяется 4 раза), «Пока эти пули летят» (строчка повторяется 3 раза).

Эмфатические паузы - перед и после заключительного высказывания-рефрена: «..Пока эти пули летят / в тебя и в меня...»), предают иллюзию незаконченности главы. Автор предлагает сотрудничество с читателем - поразмыслить о смысле и назначении своего «пребывания» на земле.

Афористичные 4-х-стишья: «Ну что же, / на то мы и люди / чтоб всё понимать. / На то мы и люди, / чтоб верить / в бессмертные сны...» и «Пока эти пули летят, / мы 
должны / успеть / вырастить хлеб, / землю спасти, / песню сложить» [3, с. 188-189] вносят оптимистические штрихи в философское рассуждение о жизни и смерти.

\section{Заключение}

Выявив современное звучание темы «войны и «мира»в поэме «Двести десять шагов», определив роль анализируемой поэмы в поэмном творчества Р.И. Рождественского, мы пришли к выводу: поэмой «Двести десять шагов» Р.И. Рождественским была создана новая модификация лирико-публицистической поэмы, в результате сочетания лиризма патетики, сомнения - восторженности, монументальности - «революционного романтизма» - патриотизма, риторичности - искренности, острой субъективности - отстранённой объективности. В поэме отразилась эволюция нравственно-эстетические принципов поэта, его отношение к актуальным проблемам планетарного значения.

\section{Примечания:}

1. Рождественский Р. Шаги истории: за строкой поэмы // Литературная газета. 20 декабря. 1978. С. 3.

2. Жегис В. Что-то нужно досказать: беседа с Р. Рождественским // Литературная газета. 2 мая 1980. С. 3.

3. Рождественский Р.И. Семь поэм. М.: Мол. гвардия, 1982.

4. Потебня А.А. Теоретическая поэтика: Учеб. пособие для студ. филол. фак. высш. учеб. заведений /Состав., вступ. ст. и коммент. А.Б. Муратова. М.: Издательский центр «Академия». 2003.

5. Литературный энциклопедический словарь / Под общ. ред. В.М. Кожевникова, П.А. Николаева. Редкол.: Л.Г. Андреев, Н.И. Балашов, А.Г. Бочаров и др. М.: Сов. Энциклопедия. 1987.

6. Мальгин А.В. Беседы о поэме (Интервью критика с Е. Евтушенко. Р. Рождественским. Л. Озеровым, Е. Исаевым, И. Шкляровским, А. Вознесенским). М.: Знание, 1990. С. 19-23.

7. Дементьев А. «Извините, что мы н-немножко одеты...» / Роберт Рождественский: удостоверение личности. М.: Эстепонт, 2002. С. 355- 358.

8. Поэт и время. Рублика: Мир социализма: литература и искусство. Диалог // Литературная газета. 5 ноября 1980. № 45. С. 3. 1990.

9. Мальгин А.В. Рождественский. Очерк творчества. М.: Художественная литература.

\section{References:} 1978. S. 3.

1. Rozhdestvenskii R. Shagi istorii: za strokoi poemy // Literaturnaya gazeta. 20 dekabrya

2. Zhegis V. Chto-to nuzhno doskazat': beseda s R. Rozhdestvenskim // Literaturnaya gazeta. 2 maya 1980. S. 3.

3. Rozhdestvenskii R. I. Sem' poem. M.: Mol. gvardiya, 1982.

4. Potebnya A.A. Teoreticheskaya poetika: Ucheb. posobie dlya stud. filol. fak. vyssh. ucheb. zavedenii /Sostav., vstup. st. i komment. A.B. Muratova. M.: Izdatel'skii tsentr «Akademiya». 2003.

5. Literaturnyi entsiklopedicheskii slovar' / Pod obshch. red. V.M. Kozhevnikova, P.A. Nikolaeva. Redkol.: L.G. Andreev, N.I. Balashov, A.G. Bocharov i dr.M.: Sov. Entsiklopediya. 1987.

6. Mal'gin A.V. Besedy o poeme (Interv'yu kritika s E. Evtushenko. R. Rozhdestvenskim. L. Ozerovym, E. Isaevym, I. Shklyarovskim, A. Voznesenskim). M.: Znanie, 1990. S. 19-23.

7. Dement'ev A. «Izvinite, chto my n-nemnozhko odety..» / Robert Rozhdestvenskii: udostoverenie lichnosti. M.: Estepont, 2002. S. 355- 358.

8. Poet i vremya. Rublika: Mir sotsializma: literatura i iskusstvo. Dialog // Literaturnaya gazeta. 5 noyabrya 1980 . № 45 . S. 3 . 1990.

9. Mal'gin A.V. Rozhdestvenskii. Ocherk tvorchestva. M.: Khudozhestvennaya literatura. 
УДК 82.0

Современные темы в поэме «Двести десять шагов» Р.И. Рождественского

Нина Яковлевна Сипкина

Хакасский государственный университет им. Н.Ф. Катанова, Российская Федерация 655000 Республика Хакасия, г. Абакан, Ленина пр., 90

Кандидат филологических наук

E-mail: sipkina.nina@yandex.ru

Аннотация. В данной статье рассматривается тематическое содержание поэмы «Двести десять шагов» Р. И. Рождественского в контексте литературного процесса 1970-х гг. Научная новизна исследуемого материала состоит в том, что впервые в отечественном литературоведении изучается одна из значимых поэм в творчестве Р.И. Рождественского. В литературоведческом исследовании анализируются главы поэмы, посвященные темам «войны» и «мира», раскрываются нравственно-эстетические принципы поэта, его отношение к актуальным проблемам мирового сообщества.

Ключевые слова: Р.И. Рождественский; поэма; «Двести десять шагов»; тема; война; мир; нравственно-эстетические принципы; структура; стиль; образы-тропы; лиризм; публицистичность. 